\title{
A SPECTRUM OF VERTEBRAL FUSION DEFECTS
}

\section{Prabahita baruah ${ }^{1}$, Krishna Kanta Biswas ${ }^{2}$, Pradipta Ray Choudhury *3.}

${ }^{1}$ Assistant professor, department of Anatomy, Silchar Medical College, Assam, India.

${ }^{2}$ Demonstrator, department of Anatomy, Silchar Medical College, Assam, India.

${ }^{*}$ Assistant professor, department of Anatomy, Silchar Medical College, Assam, India.

\section{ABSTRACT}

Any congenital or acquired abnormality in the vertebral column is of interest for radiologist, orthopedician, forensic pathologist, neurologist and clinical anatomist. Such abnormality in the vertebrae may be either asymptomatic or may limit our movements because of the important structures related to them.

During the osteology demonstration session for medical undergraduate students, we have found a few abnormal vertebrae of different regions of the spinal column.

The clinical implications and embryological significance of these specimens is discussed here.

KEY WORDS: Vertebral Synostosis, Sacralisation, Lumbarisation, Occipitalisation.

Address for Correspondence: Dr. Pradipta Ray Choudhury, Assistant professor, department of Anatomy, Silchar Medical College, Assam, India. E-Mail: prcanatomist@gmail.com.

Access this Article online

Quick Response code

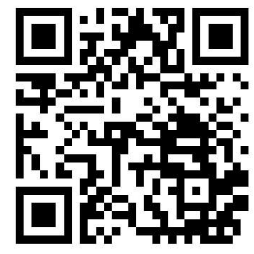

DOI: $10.16965 /$ ijar.2018.307

Journal Information

International Journal of Anatomy and Research

ICV for 2016 ISSN (E) 2321-4287 | ISSN (P) 2321-8967

90.30 https://www.ijmhr.org/ijar.htm

DOI-Prefix: https://dx.doi.org/10.16965/ijar

Article Information

Received: 03 Jul 2018

Peer Review: 03 Jul 2018

Revised: None
Accepted: 13 Aug 2018

Published (O): 05 Sep 2018

Published (P): 05 Sep 2018

\section{INTRODUCTION}

Developmental errors of vertebrae are extremely variable, involving from one level only to multiple defects throughout the length of the spine and affecting any part of the vertebrae [1]. Various vertebral anomalies of anatomic interest have been reported viz.; occipitalisation, sacralisation, lumbarisation, vertebral synostosis etc [2].

Spine formation is an intricate and highly regulated process. Any disruption in this process can result in vertebral anomalies. These defects can cause compression of the spinal cord due to deformation of the vertebral canal, spinal curvature, and alterations of the shape and number of vertebrae [3].

Vertebral fusion at single or multiple levels is referred to as block vertebrae or spinal fusion or vertebral synostosis [4]. Congenital vertebral fusion most commonly involves cervical region, followed by thoracic and lumbar regions [5].

Occipitalization represents the most cephalic 'blocked' vertebra encountered in the spine [6]. It is characterized by complete or partial fusion of the atlas to the base of the occipital bone [7].

Fusion of thoracic vertebrae, although less frequent than cervical one, is due to ossification of anterior longitudinal ligaments [8].

Lumbosacral transitional vertebrae (LSTV) occur as a congenital anomaly in the segmentation of lumbosacral spine [9]. In LSTV, either the fifth lumbar vertebra may show assimilation to the sacrum (sacralization), or the first sacral vertebra may show transition to a lumbar configuration (lumbarisation) [10]. 
Spina bifida (split spine) is a congenital vertebral defect that occurs due to failure of the halves of the embryonic neural vertebral arch to fuse [11].

A study was conducted on the vertebral bones to observe for anatomical variations in this part of North East India.

\section{MATERIALS AND METHODS}

Adult dry vertebrae of all the regions were collected and studied to observe for any abnormal fusion between the vertebrae or any fusion defect for a period of five years from December 2011 to December 2016, in the Department of Anatomy, Silchar Medical College, Silchar.

After thorough study, eight vertebral bones of different levels of vertebral column were found with fusion defect. The anomalous vertebral bones were then studied in detail and their photographs were taken. The study is being applied for approval by ethical committee of the institute.

\section{RESULTS AND OBSERVATIONS}

Among the eight vertebrae under study, one case of occipitalization of atlas, one case of two fused thoracic vertebrae, three cases of Sacralisation of fifth lumbar vertebrae (partial or complete), one case of lumbarisation of $1^{\text {st }}$ sacral vertebra, one case of spina bifida of lumbar vertebra and one case of sacralised fifth lumbar vertebra with partial bony fusion of left sacroiliac joint were observed.

Fig. 1: Occipitalization of Atlas: anterior view (1A), posterior view (1B).
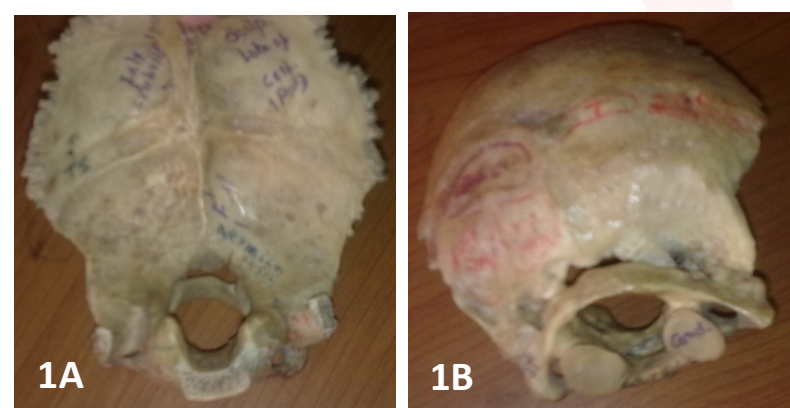

Occipitalization of atlas: the anterior arch and lateral masses of the atlas are fused with the occipital bone, but the posterior arch remain unfused. Foramen magnum is oval in shape with anterior-posterior and transverse Diameter being $23 \mathrm{~mm}$ and $24 \mathrm{~mm}$ respectively. Superior articular facets of the atlas on both left and right sides were completely fused with the corresponding occipital condyles (figure-1A and $1 B$ ).

Block vertebra in thoracic region shows fusion of two adjoining typical vertebrae, at the region of articular facets and lamina on both sides; with no other part fused including the spinous processes. The inter-vertebral disc space is maintained with a definitive intervertebral foramen. The costal facet is well defined (Figure no.2A and 2B).

Fig. 2: Fused thoracic vertebrae: posterior view $(2 A)$ and lateral view (2B).
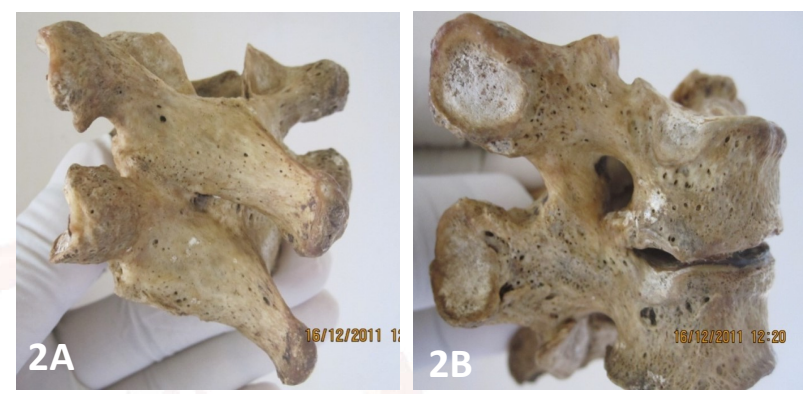

Sacralisation: In lumbosacral region, 3 cases of fusion between 5 th lumbar vertebra and first sacral vertebra are observed. Out of three sacralised bones, in two specimens, (figure no. $3 A$ and $B$ ) fifth lumbar vertebra has united with the first sacral vertebra in the midline and on both sides.

Fig. 3: $A$ and $B$ showing fifth lumbar vertebra united with the first sacral vertebra in the midline and on both sides. (a) and (b) are ventral and dorsal view of the vertebrae respectively.
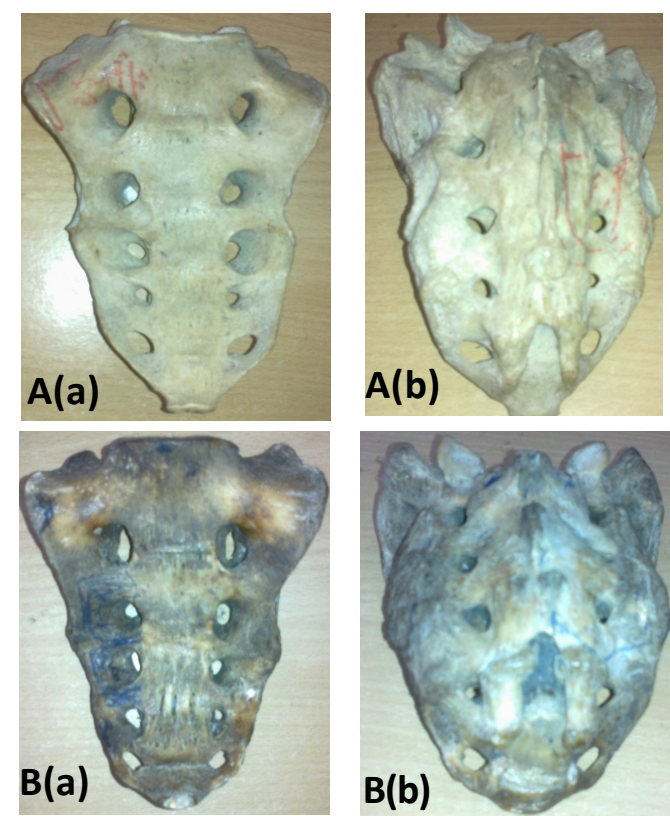

In the remaining one, (figure no.4a) the body is not completely fused with the $1^{\text {st }}$ sacral vertebra in the ventral aspect. 
All the 3 bones are presented with six vertebral bodies, five pairs of sacral foramina (instead of four) both on the pelvic and dorsal surfaces of the sacrum; sacral hiatus and sacral cornua appeared to be normal in all the three cases.

Fig..4: sacralisation with $5^{\text {th }}$ lumber vertebra not fused with the sacrum in midline ventrally (4a) but complete fusion dorsally (4b).
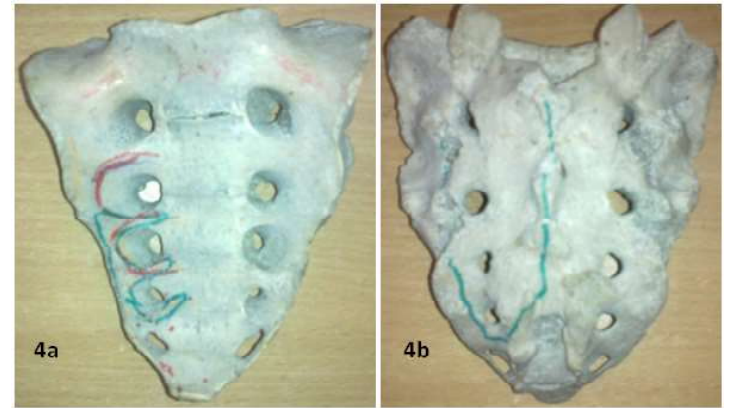

Lumbarisation: demonstrates partial lumbarisation of the first sacral vertebrae on left side. The sacrum has three distinct ventral and dorsal sacral foramina. Partial lumbarisation on left side is combined with presence of distinct transverse process on left side. On the right side the transverse process of first sacral vertebra is fused completely with that of second sacral vertebra on ventral aspect while this fusion was incomplete on dorsal aspect. The bodies of both vertebrae were completely separated from each other both ventrally and dorsally with presence of distinct intervertebral space (Figure no.5a and $5 b)$.

Fig. 5: partial lumbarisation of the first sacral vertebrae (5a, $5 \mathrm{~b}$ ventral and dorsal aspects respectively).
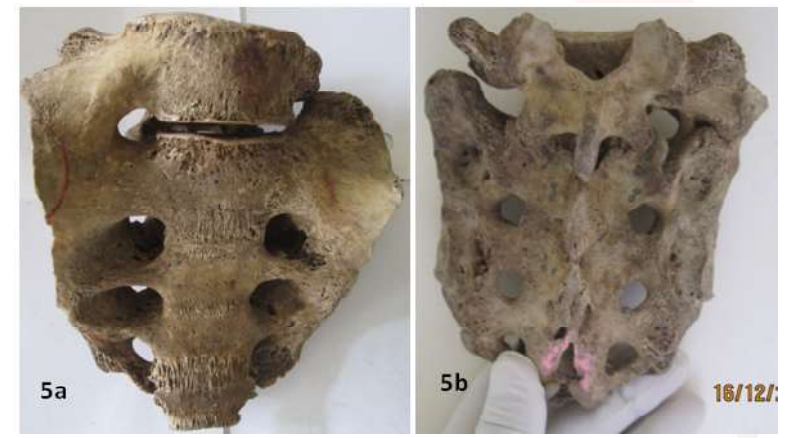

Bony fusion of sacroiliac joint: the bone shows that the sacroiliac joint has been ossified partially on left side. There is bony synostosis between the ala of sacrum and the auricular surface of ilium in the upper $1 / 4^{\text {th }}$ of the sacroiliac joint. The sacrum is also presented with complete sacralisation of $5^{\text {th }}$ lumbar vertebra with 5 pairs of ventral \& dorsal sacral foramina (figure no.6a and 6b).
Fig. 6: partial bony synostosis of the sacroiliac joint. $6 \mathrm{a}, 6 \mathrm{~b}$ are ventral and superior view respectively.

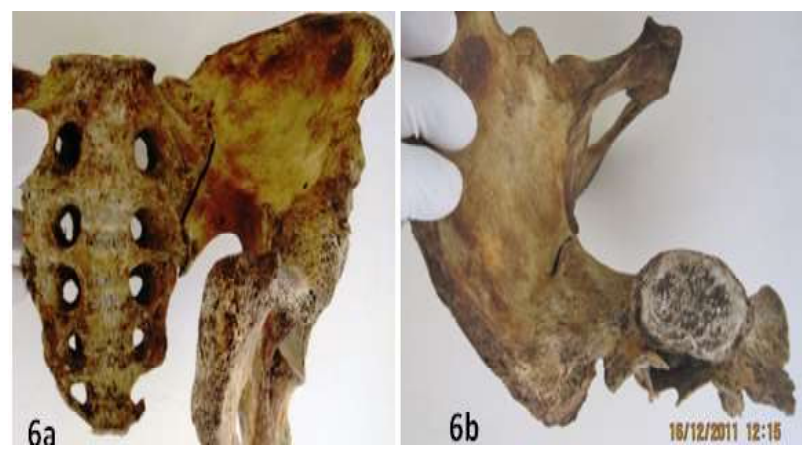

Spina bifida: A lumbar vertebra is found with the lamina on left side failed to fuse with opposite side lamina and the spinous process, leaving a distinct gap between left lamina and the spinous process (figure no.7).

Fig. 7: Dorsal view of the lumber vertebra showing spina bifida.

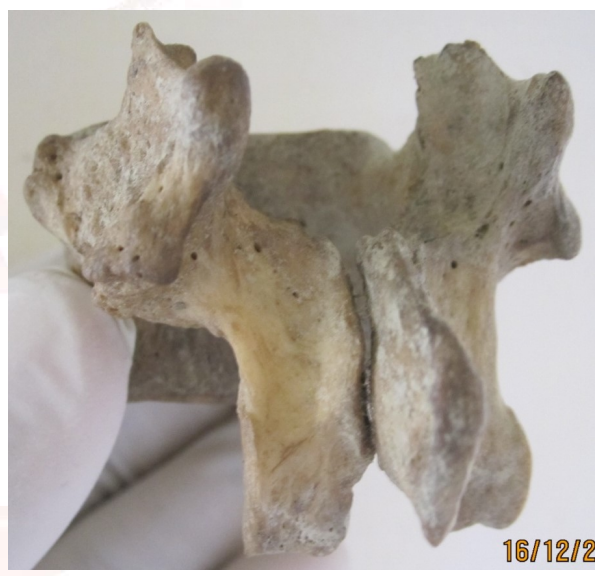

\section{DISCUSSION}

The fusion of two or more vertebrae can be congential or acquired. Congenital fusion is due to failure of segmentation of sclerotomes at certain levels at the time of organogenesis ${ }^{4}$. It has also been hypothesised that decreased local blood supply during $3^{\text {rd }}$ to $8^{\text {th }}$ week of development results in inappropriate segmentation [12]. Though rare, acquired fusion of vertebrae is secondary to trauma, tuberculosis or other infections and juvenile rheumatoid arthritis [13]. Vertebral fusion anomalies are likely to be associated with disturbance of Pax-1 gene expression in developing vertebral column [14].

The block vertebrae may cause restricted movements, premature degenerative changes and associated neurological deficits. The symptoms may vary as per the extent and level of vertebral fusion [15]. 
Occipitalization of atlas, the most cephalic 'blocked' vertebra, is due to failure in segmentation and separation of the most caudal occipital sclerotome and first cervical sclerotome during fourth week of intrauterine life ${ }^{6}$. The anomalies pertaining to craniovertebral junction is of great importance because of the presence of vertebral artery and first cervical nerve on the superficial aspect of atlas. Compression of the vertebral artery can compromise blood flow to the brain; compression of first cervical nerve can cause neurological symptoms [16].

The incidence of atlanto occipital fusion ranges from 0.14 to $0.75 \%$ of the population, with both sexes being equally affected ${ }^{6}$. The occipitocervical synostosis can be complete or incomplete; complete one is more common than the partial [16].

The incidence of fused thoracic vertebrae varied from $1.6 \%$ to $4.16 \%$ in literature [15]. Clinically the fused thoracic vertebrae can present with congenital scoliosis early in life and shortening of trunk with scoliosis and / or lordosis in older children ${ }^{17}$. Massive fusion of thoracic vertebrae can narrow the thorax leading to respiratory distress [18].

The thoracic or lumbar vertebral fusion is an autosomal recessive disorder [19]. Lumbosacral transitional vertebrae (LSTV) are most common congenital anomalies of the lumbosacral spine. The lumbosacral spine, besides protecting the spinal cord and spinal nerves, also plays an important role in posture and locomotion [20].

LSTV is linked to its embryological development. Vertebra receives contribution from caudal half of one sclerotome and cranial half of succeeding sclerotome. LSTV are caused by border shifts. Sacralisation of fifth lumbar vertebra is due to cranial shift and the lumbarisation of first sacral segment is due to caudal shift ${ }^{21}$. Complete transition results in numerical abnormalities of the lumbar and sacral segments. LSTV, in most cases, however, is incomplete or unilateral but can also be bilateral and complete [20].

Literature is unclear about exact origin of LSTV; it is likely a product of both genetic predisposition (Hox10 gene mutation) and developmental influences [22]. Wellik et al., showed that in absence of Hox 11 function, sacral vertebrae are not formed and instead these vertebrae assume a lumbar identity. Again in absence of Hox 10 function, no lumbar vertebrae are formed. Thus these studies showed that, the normal patterning of lumbar and sacral vertebrae as well as the changes in the axial pattern, such as Lumbosacral transition vertebrae, result from mutations in the Hox10 and Hox11 paralogous genes [23].

LSTV can cause low back pain which may result from the pressure on nerve trunks, ligamentous strain or compression of soft tissues between bony joints [9]. The incidence of disc herniation is also found to be higher in LSTV [24].

Lumbarisation of first sacral vertebra is reported with a very low incidence of $2 \%$, as compared to sacralisation of fifth lumbar vertebrae [25]. Complete lumbarisation of first sacral vertebrae, leading to increase in the number of lumbar vertebrae, is a rare occurrence. Partial lumbarisation, similar to the present case, can be seen with distinct disc space between the S1 and S2 [26].

Incidence of sacralisation of lumbar vertebrae was found to be $6.6 \%$ [9], $11.1 \%$ [27] and $20.8 \%$ [28] in different studies.

Spina bifida results from non-closure of the neural tube during embryonic development. It is classified into two main groups: open and closed variety. It is thought to arise as a result of genetic and environmental factors [29]. The most frequent location of spina bifida is the lumbosacral region (50\%), followed by the thoracolumbar region (35\%) [30].

\section{CONCLUSION}

Awareness of vertebral anomalies is of interest to clinical anatomist, forensic experts and also to clinicians. Knowledge of such abnormality is important for radiologists during diagnostic imaging studies. Awareness of this abnormality is a prerequisite for a neurosurgeon to prevent complications during and after the spinal manipulations. Incorrect numbering may create complication during administration of anaesthetics in patients with LSTV.

\section{Conflicts of Interests: None}




\section{REFERENCES}

[1]. Ruth Wynne-Davies. Congenital vertebral anomalies: aetiology and relationship to spina bifida cystica. Journal of Medical Genetics 1975; 12:280.

[2]. Thomas D, Kulkarni BG. A case of fusion of thoracic vertebra. Journal of Ayurveda and Holistic Medicine 2013; 1 (5): 23-26.

[3]. Frederick F, Vandermark RE. "Sagittal Cleft (Butterfly) Vertebrae." Journal of Bone and Joint Surgery 1945: 695-698.

[4]. Kulkarni V, Ramesh BR. A spectrum of vertebral synostosis. International Journal of Basic and Applied Medical Sciences, 2012; 2(2): 71-77.

[5]. Soni P, Sharma V, Sengupta J. Cervical vertebral anomalies- incidental findings on lateral cephalograms. The Angle Orthodontist 2008; 78(1): 176-180.

[6]. Guebert GM, Yochum TR, Rowe L. Congenital anomalies and normal skeleton variants. In: Yochum TR, Rowe LJ, eds. Essentials of Skeletal Radiology. Baltimore. Williams \& Wilkins; 1987. p. 197-306.

[7]. Tun K, Okutan O, Kaptanoglu E, Gok B, Solaroglu I, Beskonakli E. Inverted hypertrophy of occipitalcondyles associated with atlantooccipital fusion and basilar invagination: a case report. Neuroanatomy 2004; 3: 43-45.

[8]. Elster AD. Bertolotti's syndrome revisited transitional vertebrae of the lumbar spine. Spine 1989;14(12):1373-7

[9]. Khairnar KB, Rajale MB. Sacralization of Lumbar Vertebra. Indian Journal of Basic \& Applied Medical Research 2013; 2(6):510-514.

[10]. Saha DK, Dasgupta H, Biswas S, Paul M, Ghosh R. et. al. Sacralization of the 5th lumbar vertebra and elongated sacral hiatus. Indian Journal of Basic and Applied Medical Research 2014; 3(3):95-99.

[11]. Moore KL, Persaud TVN. The Developing Human: Clinically oriented embryology. $8^{\text {th }}$ ed. Philadelphia: Saunders; 2009. p350

[12]. Wazir S, Mahajan A. Fusion of axis with third cervical vertebra-a case report. Indian J Fundamental Appl Sci 2011; 1 (4): 164-166.

[13]. Erdil H, Yildiz N, Cimen M. Congenital fusion of cervical vertebrae and its clinical significance. Journal of Anatomical Society of India 2003; 52(2): 125127.

[14]. Sherekar SK, Yadav YR, Basoor AS, Baghel A, Adam N. Clinical implications of alignment of upper and lower cervical spine. Neurological society of India 2006; 54: 264-267.
[15]. Nazeer M et al., Fusion of Typical Thoracic Vertebrae: A Case Report .Sch. J. App. Med. Sci. 2015; $3(1 \mathrm{~A}): 24-28$.

[16]. Jadhav SD, Ambali MP, Patil RJ, Doshi MA, Roy PP. Assimillation of atlas in Indian dry skulls. JKIMSU. 2012;1:102-6.

[17]. Al Kaissi A, Ghachem MB, Nassib N, Ben Chechida F, Kozlowski K; Spondylocarpotarsal synostosis syndrome (with a posterior midline unsegmented bar). Pub Med Skeletal Radiology 2005; 34(6): 364-6.

[18]. Bhargava S. Radiological Differential Diagnosis. 1st ed. New Delhi: Jaypee Brothers. 2005. p528.

[19]. Gunderson $\mathrm{CH}$, Greenspan RH, Glaser GH, Lubs HA. The Klippel Feil syndrome: genetic and clinical reevaluation of cervical fusion. Medicine 1967; 46: 491-512.

[20]. Adibatti M, Asha K. Lumbarisation of the first sacral vertebra a rare form of lumbosacral transitional vertebra. Int. J. Morphol. 2015; 33(1):48-50.

[21]. Sharma VA, Sharma DK, Shukla CK, Osteogenic study of lumbosacral transitional vertebra in central india region. J. Anat Soc India. 2011; 60(2):212-17.

[22]. Wazir S. Sacralisation of Lumbar Vertebrae, Int J Anat Res 2014; 2(2):386-89.

[23]. Wellik DM, Capecchi MR. Hox 10 and Hox 11 genes are required to globally pattern the mammalian skeleton. Science 2005; 301(5631): 363-367.

[24]. Williams, PC. The lumbosacral spine, emphasizing conservative management. New York, McGraw-Hill Book Company 1965. 27-32.

[25]. Cheng JS, Song JK. Anatomy of the sacrum. Neurosurg. Focus 2003; 15(2):3.

[26]. Meschan I. An Atlas of Anatomy Basic to Radiology. Philadelphia, W. B. Saunders. 1985. p.511-2.

[27]. Darathi K, Nagar SK, Ojaswini M, Dipali T, Paras S, Sucheta P. A study of sacralisation of fifth lumbar vertebra in Gujrat. National Journal of Medical Research 2012;2(2):211-3.

[28]. Magora A, Schwartz A. Relation between the low back pain syndrome and X-ray findings.Transitional vertebra (mainly sacralization) Scan J Rehabil Med 1978, 10: 135-45.

[29]. Basaloglu HK. et al., Spina Bifida: Morphological Features, Molecular Regulations and Signal Pathways: J Spine 2017; 6(1):1-6.

[30]. Salim D, Mohammed AE, Alla AM. Spina bifida in Sudan. J Neurol Neurosci. 2014; 5: 1-8.

How to cite this article:

Prabahita baruah, Krishna Kanta Biswas, Pradipta Ray Choudhury. A SPECTRUM OF VERTEBRAL FUSION DEFECTS. Int J Anat Res 2018;6(3.3):5667-5671. DOI: 10.16965/ijar.2018.307 